\title{
Hydroxyapatite Formation on Ca-P-O Coating Prepared by MOCVD
}

\author{
Mitsutaka Sato ${ }^{1}$, Rong $\mathrm{Tu}^{2}$, Takashi Goto ${ }^{2}$, Kyosuke Ueda $^{1}$ and Takayuki Narushima ${ }^{1}$ \\ ${ }^{1}$ Department of Materials Science, Graduate School, Tohoku University, Sendai 980-8577, Japan \\ ${ }^{2}$ Institute for Materials Research, Tohoku University, Sendai 980-8577, Japan
}

Ca-P-O coatings of $\alpha$-tricalcium phosphate ( $\alpha$-TCP) and hydroxyapatite (HAp) films were prepared on commercially pure Ti (CP-Ti) by MOCVD using $\mathrm{Ca}(\mathrm{dpm})_{2}$ and $\left(\mathrm{C}_{6} \mathrm{H}_{5} \mathrm{O}\right)_{3} \mathrm{PO}$ precursors. The behavior of apatite formation on the Ca-P-O coatings was investigated by immersing specimens in a Hanks' solution. An apatite phase has regenerated on the $\alpha$-TCP coating after 1 day, and has covered the whole specimen surface after $14 \mathrm{~d}$. On the HAp coating, an apatite phase has regenerated after $1 \mathrm{~h}$ and has covered the whole surface after $6 \mathrm{~h}$. The microstructure of the regenerated apatite phase on the HAp coating has changed from a needle-like to a network texture after $12 \mathrm{~h}$. [doi:10.2320/matertrans.MRA2008097]

(Received March 24, 2008; Accepted May 8, 2008; Published July 2, 2008)

Keywords: metal organic chemical vapor deposition, $\alpha$-tricalcium phosphate, hydroxyapatite, Hanks' solution

\section{Introduction}

Calcium phosphate, such as hydroxyapatite $\left(\mathrm{Ca}_{10}\left(\mathrm{PO}_{4}\right)_{6}-\right.$ $\left.(\mathrm{OH})_{2}, \mathrm{HAp}\right)$ and $\alpha-, \beta$-tricalcium phosphate $\left(\mathrm{Ca}_{3}\left(\mathrm{PO}_{4}\right)_{2}\right.$, TCP), has been used as artificial bones and teeth because of its excellent biocompatibility, bioactivity and biodegradability. ${ }^{1)} \mathrm{Ti}$ and its alloys have been used as tooth implant and hipbone joints due to their good mechanical properties, corrosion resistance and biocompatibility. ${ }^{2,3)}$ However, a long period of time, typically 3 months, would be needed to fix $\mathrm{Ti}$ implants with bones without applying mechanical force during the fixation period. In order to reduce the fixation period, Ti implants are coated with bio-ceramics, usually calcium phosphate, because such coating is particularly effective in fixing in the initial stage. ${ }^{1)}$ Many studies on bio-ceramic coatings prepared by plasma spray, ${ }^{4,5)}$ sol-gel ${ }^{6,7)}$ and sputtering ${ }^{8,9)}$ have been reported.

Chemical vapor deposition (CVD) is advantageous for coatings at a high deposition rate, excellent microstructure controllability and step coverage, ${ }^{10}$ ) however only a few studies on bio-ceramics applied by CVD have been reported. In a previous study, we have first prepared $\alpha$-TCP and HAp films by metal-organic chemical vapor deposition (MOCVD). ${ }^{11)}$ Single phases of $\alpha$-TCP, HAp and mixtures of $\alpha$-TCP and HAp having a dense microstructure were prepared by changing the deposition conditions, mainly the substrate temperature and total pressure. The maximum deposition rate was $6.0 \mathrm{~nm} \mathrm{~s}^{-1}, 40$ times faster than that of a sputtering method. However, there have been no reports on the regeneration of apatite (bone conductivity) on $\alpha$-TCP and HAp coatings prepared by CVD. The bone conductivity of bio-ceramic coatings can often be evaluated by apatite formation rates in a pseudo-body fluid. The apatite formation rates reported in literatures greatly scattered and there have been no comprehensive understanding of the regeneration of apatite. We have reported that the surface morphology of MOCVD Ca-T-O films would significantly affect the regeneration of apatite. ${ }^{12)}$ Therefore, bio-ceramic coatings with well-controlled microstructures should be prepared to study bone conductivity.
In this study, Ca-P-O films were prepared by MOCVD and the apatite formation behavior was investigated by immersing Ca-P-O films in a pseudo-body fluid.

\section{Experimental Procedure}

Ca-P-O films were prepared using a vertical cold-wall type CVD apparatus. ${ }^{12)} \mathrm{Ca}(\mathrm{dpm})_{2}$ (bis-dipivaloylmethanatocalcium) and $\left(\mathrm{C}_{6} \mathrm{H}_{5} \mathrm{O}\right)_{3} \mathrm{PO}$ (triphenylphosphate) source powders were heated at 523 to 573 and 493 to $533 \mathrm{~K}$, respectively. These vapors were carried into the CVD reactor by Ar carrier gas. $\mathrm{O}_{2}$ gas was separately introduced by using a double-tube nozzle and mixed with the precursor vapor in a mixing chamber placed above a substrate holder. The total gas flow rate $\left(F R_{\text {tot }}=F R_{\mathrm{Ar}}+F R_{\mathrm{O}_{2}}+F R_{\text {source vapor }}\right)$ was fixed at $3.33 \times 10^{-6} \mathrm{~m}^{3} \mathrm{~s}^{-1}$. The total pressure $\left(P_{\text {tot }}\right)$ in the CVD reactor was maintained at $0.8 \mathrm{kPa}$. The substrate temperature $\left(T_{\text {sub }}\right)$ was $1073 \mathrm{~K}$. Commercially pure titanium (CP-Ti) of $10 \times 15 \times 0.5 \mathrm{~mm}$ was used as substrate.

The deposition conditions are summarized in Table 1. The crystal structure was analyzed by X-ray diffraction (XRD). The microstructure and thickness were examined by scanning electron microscopy (SEM). A Hanks' solution was used as a pseudo-body fluid, and its components are listed in Table 2.

Table 1 Deposition conditions of Ca-P-O films.

\begin{tabular}{ll} 
Precursor Temperature, $T_{\text {prec }}$ & \\
$\mathrm{Ca}(\mathrm{dpm})_{2}:$ & $533-573 \mathrm{~K}$ \\
$\left(\mathrm{C}_{6} \mathrm{H}_{5} \mathrm{O}\right)_{3} \mathrm{PO}:$ & $493-533 \mathrm{~K}$ \\
Total gas flow rate, $F R_{\text {tot }}:$ & $3.33 \times 10^{-6} \mathrm{~m}^{3} \mathrm{~s}^{-1}$ \\
Carrier Gas & $\mathrm{Ar}$ \\
$\mathrm{Ca}(\mathrm{dpm})_{2}:$ & $0.83 \times 10^{-6} \mathrm{~m}^{3} \mathrm{~s}^{-1}$ \\
$\left(\mathrm{C}_{6} \mathrm{H}_{5} \mathrm{O}\right)_{3} \mathrm{PO}:$ & $0.83 \times 10^{-6} \mathrm{~m}^{3} \mathrm{~s}^{-1}$ \\
$\mathrm{O}_{2}$ gas flow rate, $F R_{\mathrm{O}_{2}}:$ & $1.2 \times 10^{-6} \mathrm{~m}^{3} \mathrm{~s}^{-1}$ \\
Total pressure, $P_{\text {tot }}:$ & $0.8 \mathrm{kPa}$ \\
Deposition temperature, $T_{\text {sub }}:$ & $1073 \mathrm{~K}$ \\
Deposition time: & $0.9 \mathrm{ks}$ \\
Substrate: & $\mathrm{CP}-\mathrm{Ti}$ \\
\hline
\end{tabular}


Table 2 Chemical composition of Hanks' solution.

\begin{tabular}{ccccccccc}
\hline & \multicolumn{5}{c}{ Concentration $\left(\mathrm{mg} / \mathrm{m}^{3}\right)$} \\
\hline $\mathrm{NaCl}$ & $\mathrm{KCl}$ & $\mathrm{Na}_{2} \mathrm{HPO}_{4}$ & $\mathrm{KH}_{2} \mathrm{PO}_{4}$ & $\mathrm{MgSO}_{4}$ & $\mathrm{MgCl}_{2}$ & $\mathrm{CaCl}_{2}$ & $\mathrm{Glucose}$ \\
\hline 8.00 & 0.40 & $4.79 \times 10^{-2}$ & $6.00 \times 10^{-2}$ & $4.88 \times 10^{-2}$ & $4.68 \times 10^{-2}$ & 0.14 & 1.00 & \\
\hline
\end{tabular}

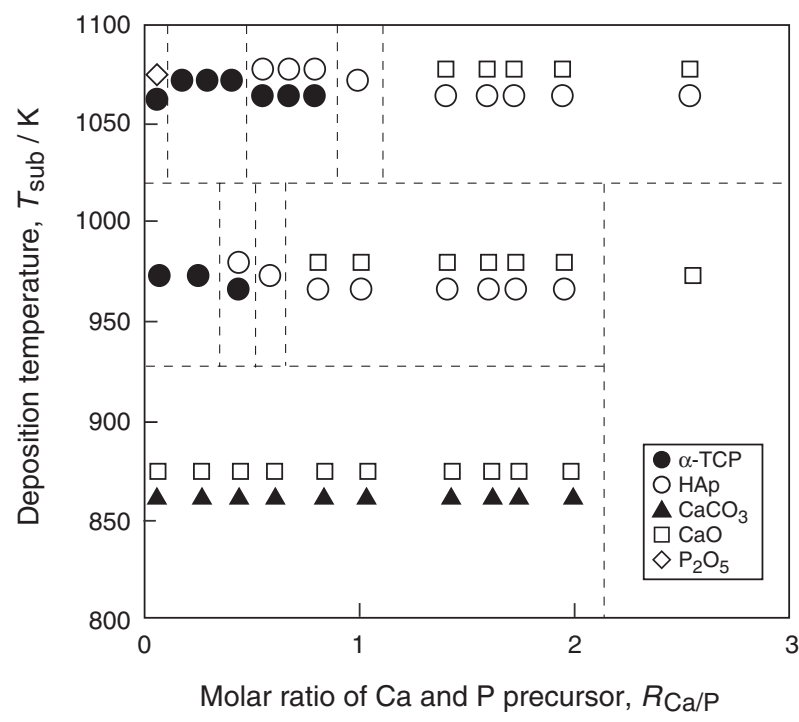

Fig. $1 T_{\mathrm{sub}}-R_{\mathrm{Ca} / \mathrm{P}}$ phase formation diagram of Ca-P-O films at $P_{\mathrm{O}_{2}}=$ $0.32 \mathrm{kPa}$ and $P_{\text {tot }}=0.8 \mathrm{kPa}$.

Specimens were ultrasonically cleaned in ethanol and immersed in the Hanks' solution. The temperature in an incubator was maintained at $310 \mathrm{~K}$. The immersion time ranged from $0.5 \mathrm{~h}$ to $2 \mathrm{w}$, and the solution was changed every $1 \mathrm{w}$. After the immersion test, specimens were washed with distilled water and then dried. The crystal structure and microstructure after the immersion test were analyzed by XRD and SEM, respectively.

\section{Results and Discussion}

\subsection{Ca-P-O coating on CP-Ti substrate}

Figure 1 shows a CVD phase formation diagram of $\mathrm{Ca}$ P-O films as functions of $T_{\text {sub }}$ and $R_{\mathrm{Ca} / \mathrm{P}}$. CaO phase formed mainly in a low $T_{\text {sub }}$ and a high $R_{\mathrm{Ca} / \mathrm{P}}$ regions, whereas $\mathrm{P}_{2} \mathrm{O}_{5}$ phase formed in a high $T_{\text {sub }}$ region. At $T_{\text {sub }}=873 \mathrm{~K}$, no Ca$\mathrm{P}-\mathrm{O}$ phase was obtained, while a mixture phase of $\mathrm{CaO}$ and $\mathrm{CaCO}_{3}$ was obtained in a wide region. At $T_{\text {sub }}=973$ and $1073 \mathrm{~K}$, the crystal structure of Ca-P-O changed depending on $R_{\mathrm{Ca} / \mathrm{P}} \cdot \alpha$-TCP in a single phase was obtained at $R_{\mathrm{Ca} / \mathrm{P}}<$ 0.3 when $T_{\text {sub }}=1073 \mathrm{~K}$ and $R_{\mathrm{Ca} / \mathrm{P}}=0.1$ to 0.4 when $T_{\text {sub }}=973 \mathrm{~K}$. HAp in a single phase was obtained at $R_{\mathrm{Ca} / \mathrm{P}}=$ 0.5 to 0.6 when $T_{\text {sub }}=973 \mathrm{~K}$ and $R_{\mathrm{Ca} / \mathrm{P}}=0.8$ to 1.0 when $T_{\text {sub }}=1073 \mathrm{~K}$.

Figure 2 shows the surface morphology of $\alpha$-TCP and HAp coatings prepared at $T_{\text {sub }}=1073 \mathrm{~K}$ and $P_{\text {tot }}=0.8 \mathrm{kPa}$. The HAp coating had a granular surface with a grain size of $2 \mu \mathrm{m}$ in diameter, and these grains consisted of further smaller grains (Fig. 2(a)). The surface morphology of the $\alpha$-TCP coating had a granular surface with a grain size of $1 \mu \mathrm{m}$ in diameter with a relatively smooth texture (Fig. 2(b)).
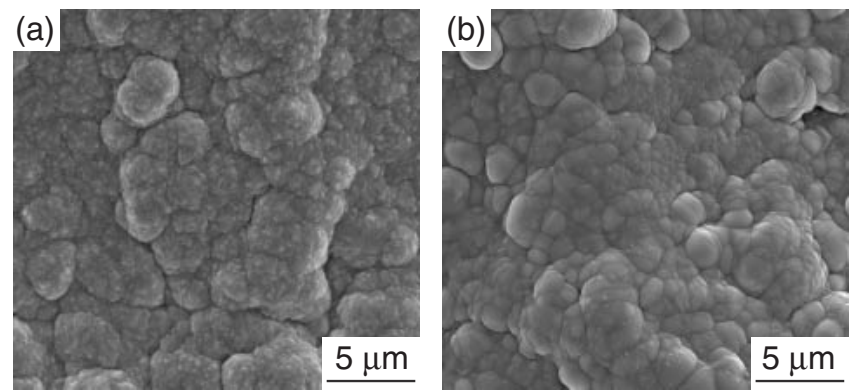

Fig. 2 Surface morphology of Ca-P-O coatings before immersion prepared at $T_{\text {sub }}=1073 \mathrm{~K}$ and $P_{\text {tot }}=0.8 \mathrm{kPa}$. (a) HAp coating, (b) $\alpha$-TCP coating.



Fig. 3 XRD patterns before and after immersion of $\alpha$-TCP coatings prepared at $T_{\text {sub }}=1073 \mathrm{~K}$. (a) before immersion, (b) $1 \mathrm{~d}$, (c) $3 \mathrm{~d}$, (d) $7 \mathrm{~d}$, (e) $14 \mathrm{~d}$.

\subsection{Immersion test}

Figure 3 shows XRD patterns of the $\alpha$-TCP coatings after immersion in the Hanks' solution from $1 \mathrm{~d}$ to $2 \mathrm{w}$. No changes of XRD patterns were observed after $7 \mathrm{~d}$, and diffraction peaks of apatite were identified at $2 \theta=25.8^{\circ}$ and $31.7^{\circ}$ after $14 \mathrm{~d}$. Although $\alpha$-TCP is known as a highly biodegradable material, ${ }^{13)}$ the $\alpha$-TCP phase remained even after $14 \mathrm{~d}$ immersion. The dense microstructure might inhibit the elution of the $\alpha$-TCP coatings.

Figure 4 shows the surface morphology of the $\alpha$-TCP coatings after immersion in a Hanks' solution. A small amount of apatite crystals were observed after $1 \mathrm{~d}$ (Fig. 4(a)), and the apatite crystals grew with increasing immersion time 

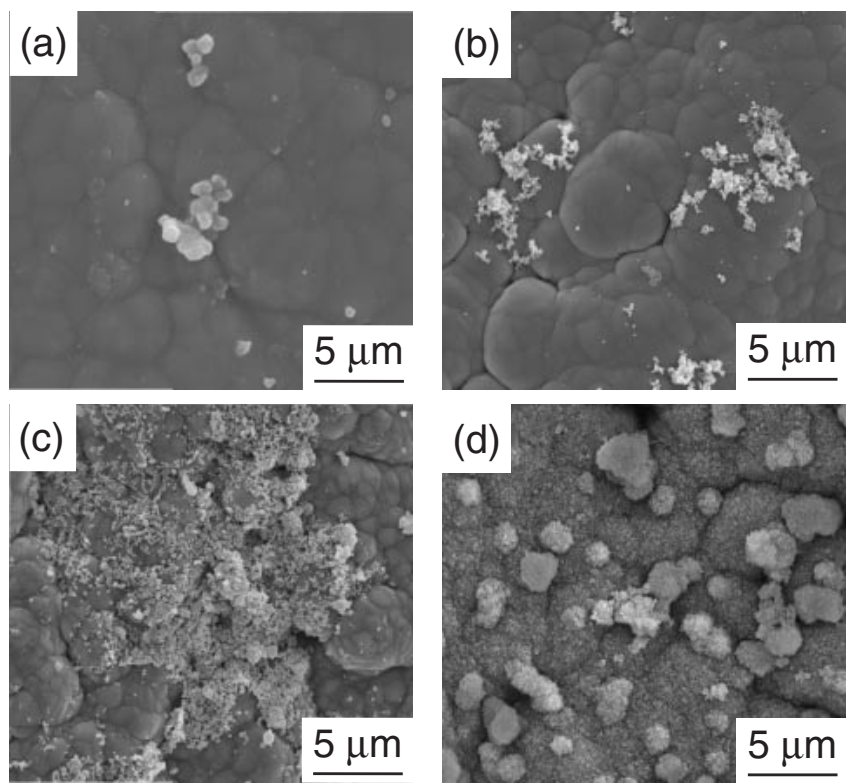

Fig. 4 Surface morphology of $\alpha$-TCP coatings prepared at $T_{\text {sub }}=1073 \mathrm{~K}$ after immersion in a Hanks' solution. (a) $1 \mathrm{~d}$, (b) $3 \mathrm{~d}$, (c) $7 \mathrm{~d}$, (d) $14 \mathrm{~d}$.

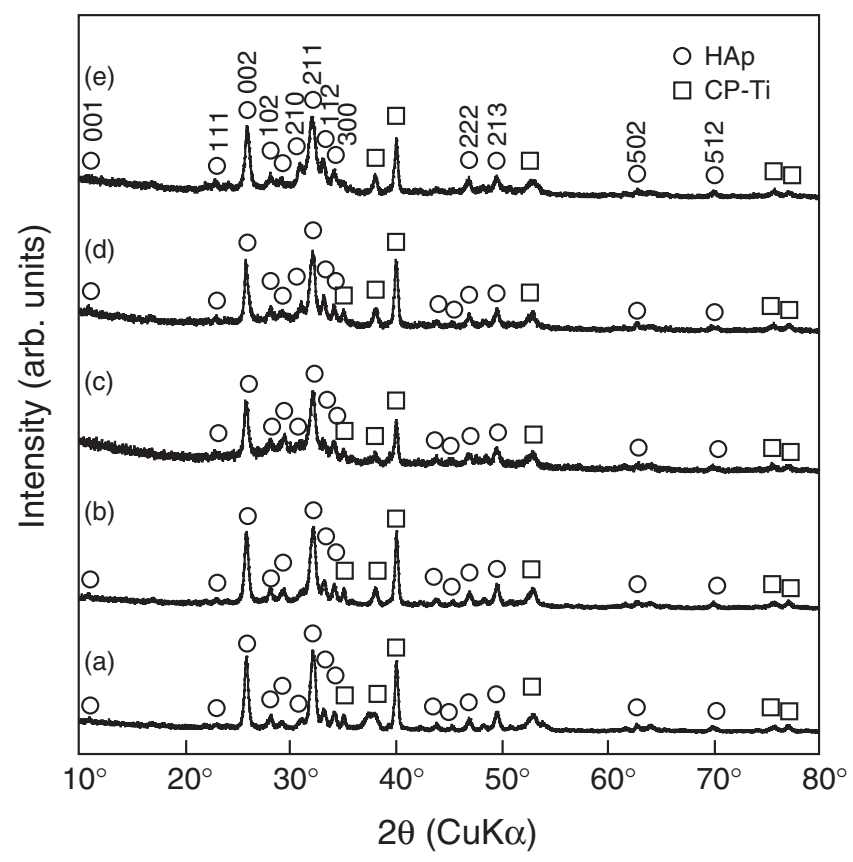

Fig. 5 XRD patterns before and after immersion of HAp coatings prepared at $T_{\text {sub }}=1073 \mathrm{~K}$. (a) before immersion, (b) $1 \mathrm{~d}$, (c) $3 \mathrm{~d}$, (d) $7 \mathrm{~d}$, (e) $14 \mathrm{~d}$.

(Figs. 4(b), 4(c)). The apatite covered the whole surface of the $\alpha$-TCP coating after $14 \mathrm{~d}$ (Fig. 4(d)).

Figure 5 shows XRD patterns of the HAp coatings after immersing in the Hanks' solution for $1 \mathrm{~d}$ to $2 \mathrm{w}$. The HAp coating had a preferred orientation of (002), and no significant change of XRD pattern was identified after immersion.

Figure 6 shows the surface morphology of HAp coating after immersion in the Hanks' solution from $1 \mathrm{~d}$ to $2 \mathrm{w}$. The surface of HAp coating was covered by apatite after $1 \mathrm{~d}$ exhibiting high bone conductivity (Fig. 6(a)). The amount of apatite increased with increasing immersion time (Fig. 6(b)).
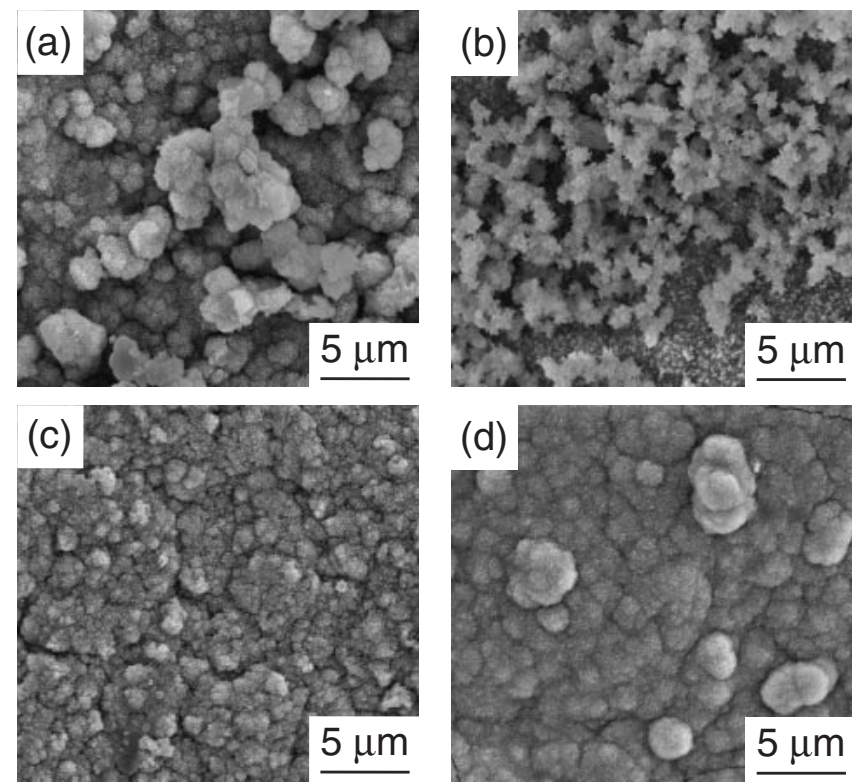

Fig. 6 Surface morphology of HAp coatings prepared at $T_{\text {sub }}=1073 \mathrm{~K}$ after immersion in a Hanks' solution. (a) $1 \mathrm{~d}$, (b) $3 \mathrm{~d}$, (c) $7 \mathrm{~d}$, (d) $14 \mathrm{~d}$.

\subsection{Apatite formation on Ca-P-O film}

Figure 7 shows the surface morphology of the HAp coatings in an initial stage of the immersion test. Many small holes were observed after $0.5 \mathrm{~h}$ (Fig. 7(a)), perhaps due to the elution of the HAp coating into solution. The apatite phase was identified at hollow places in the HAp coatings after $1 \mathrm{~h}$ (Fig. 7(b)), and the grain size of the apatite phase grew with increasing immersion time (Fig. 7(c)). The apatite phase with a needle-like texture covered the whole surface of the HAp coatings after $6 \mathrm{~h}$ (Fig. 7(d)). The microstructure of the apatite phase has changed from a needle-like to a network texture after $12 \mathrm{~h}$ (Fig. 7(e)).

The apatite formation mechanism on the bio-ceramic coatings can be assumed as illustrated in Fig. 8. The bioceramic film would be eluted into solution and the eluted ions have been trapped at the hollow places in the film. The concentration of $\mathrm{Ca}^{2+}$ and $\mathrm{PO}_{4}{ }^{3-}$ ion would be increased locally at the hollow places. The $\mathrm{Ca}^{2+}$ ions in the solution could be adsorbed at the supersaturated hollow places of $\mathrm{PO}_{4}{ }^{3-}$ ions, and the $\mathrm{PO}_{4}{ }^{3-}$ ions in the solution would be also adsorbed at the supersaturated hollow places of $\mathrm{Ca}^{2+}$ ions. Consequently, the apatite phase has nucleated and the growth has proceeded. The preferential formation of apatite at the hollow places was also observed in $\mathrm{CaTiO}_{3}$ film prepared by MOCVD. ${ }^{12)}$

In this study, the apatite formation rate on the HAp coatings was faster than that of $\alpha$-TCP coating. It is known that the elution of calcium phosphate coating must have taken place in advance of the formation of apatite. However, since the elution rate of $\alpha$-TCP should be much higher than that of HAp coating, ${ }^{14)}$ the surface morphology of $\alpha$-TCP coating would become smoother than that of HAp coating resulting in the decrease of nucleation site of apatite formation. Furthermore, the adsorbed apatite nuclei would be easily detached due to the elution of the $\alpha$-TCP coatings. On the other hand, the moderate elution rate of HAp coating might increase the concentration of $\mathrm{Ca}^{2+}$ and $\mathrm{PO}_{4}{ }^{3-}$ ions in 

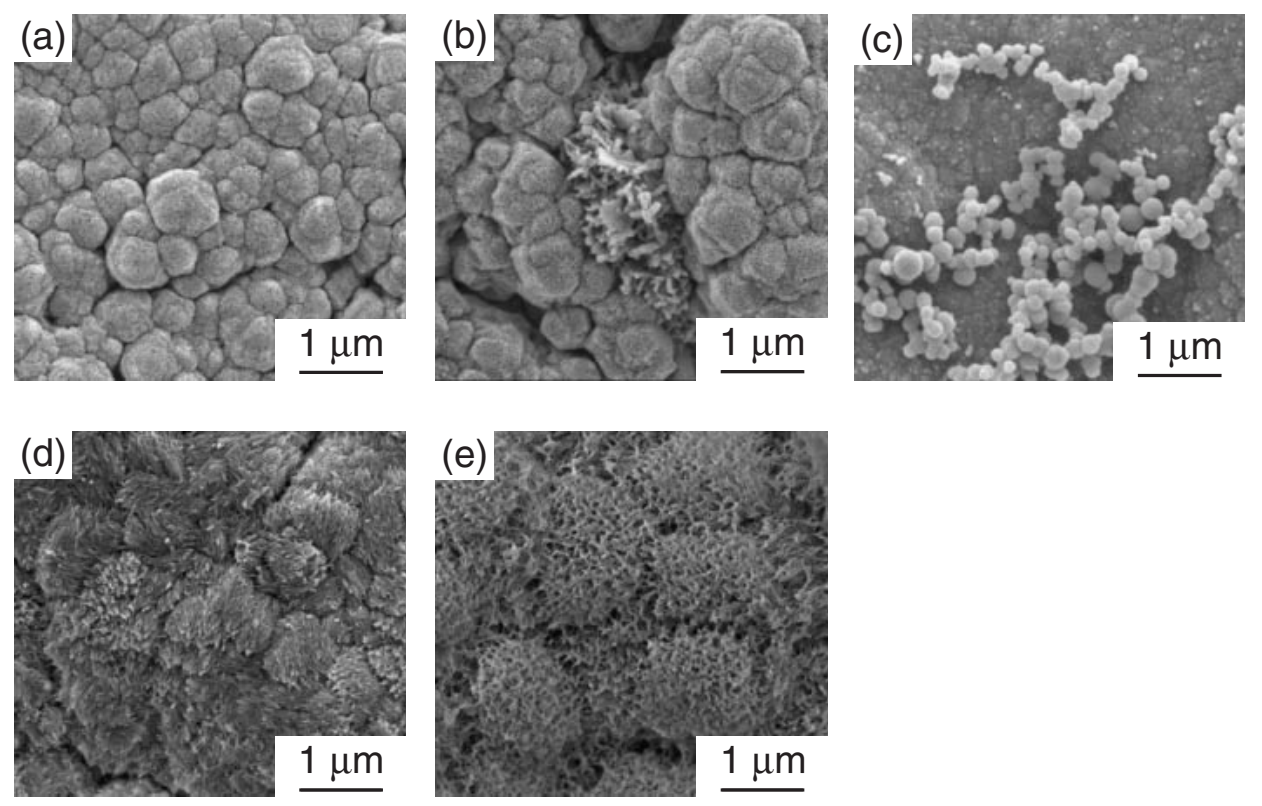

Fig. 7 Surface morphology of HAp coatings prepared at $T_{\text {sub }}=1073 \mathrm{~K}$ after immersion in a Hanks' solution. (a) $0.5 \mathrm{~h}$, (b) $3 \mathrm{~h}$, (c) $6 \mathrm{~h}$, (d) $12 \mathrm{~h}$, (e) $24 \mathrm{~h}$.

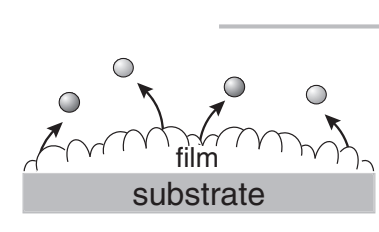

Film elutes into a pseudo body fluid.

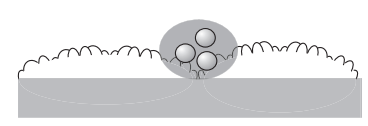

Eluted ions are trapped at hollow place of film, and concentration of $\mathrm{Ca}^{2+}$ and/or $\mathrm{PO}_{4}{ }^{3-}$ ions increases.

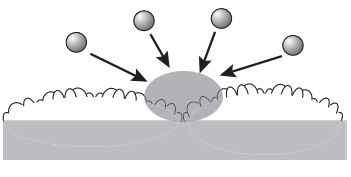

$\mathrm{Ca}^{2+}$ or $\mathrm{PO}_{4}^{3-}$ ions in a pseudo body fluid are adsorbed.

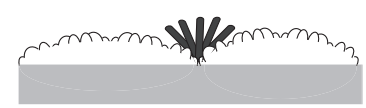

Apatite nucleats and grows.

$\mathrm{Ca}^{2+}$

Fig. 8 Apatite formation mechanism on bioceramic films.

the vicinity of the HAp coating. The numerous sub-micron pores formed due to the elution of HAp coating (Fig. 7(b)) should become the trapping points of $\mathrm{Ca}^{2+}$ and $\mathrm{PO}_{4}{ }^{3-}$ ions accelerating the formation of apatite.

Figure 9 compares the time required for the formation of apatite over the whole surface of $\mathrm{Ca}-\mathrm{Ti}-\mathrm{O}$ and $\mathrm{Ca}-\mathrm{P}-\mathrm{O}$ films prepared by MOCVD by immersion in the Hanks' solution. In our previous study, the apatite phase has covered the whole surface of the $\mathrm{CaTiO}_{3}$ coating with a smooth surface after $6 \mathrm{w}$ and that of the $\mathrm{CaTiO}_{3}$ coating with a cauliflower-like texture after $3 \mathrm{~d} .^{12)}$ The apatite formation rate changed depending on the surface morphology of the coating. This result suggests that the surface morphology should significantly affect the apatite formation. In addition, although both the $\alpha$-TCP and HAp coatings had a smooth texture, the apatite formation rates of $\alpha$-TCP and that of HAp were faster than that of the $\mathrm{CaTiO}_{3}$ coating with a smooth surface. Therefore, the faster apatite formation rate on the $\mathrm{Ca}-\mathrm{P}-\mathrm{O}$ coatings could be caused by the higher bone conductivity of $\mathrm{Ca}-\mathrm{P}-\mathrm{O}$ coating than that of Ca-Ti-O coating. Therefore, the apatite formation on bio-ceramic coating would be mainly affected by both bone conductivity and surface morphology of coating.

Table 3 summarizes the apatite formation time on bio-

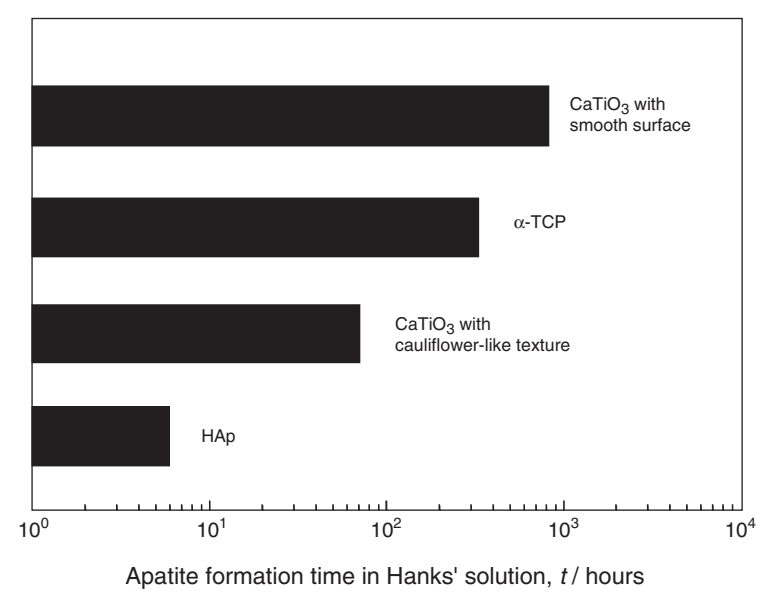

Fig. 9 Comparison of apatite formation time on MOCVD bioceramic coatings in a Hanks' solution.

ceramic coatings prepared by various methods after immersion in pseudo-body fluids. The $\mathrm{CaTiO}_{3}$ coating with a cauliflower-like texture and the HAp coating prepared by MOCVD exhibited relatively higher rates of apatite forma- 
Table 3 Comparison of apatite formation time on bioceramic sintered body and films prepared by various methods.

\begin{tabular}{|c|c|c|c|c|}
\hline Bioceramics & Preparation method & Pseudo-body fluid & $\begin{array}{l}\text { Apatite formation } \\
\text { (hours) }\end{array}$ & Reference \\
\hline HAp & MOCVD & Hanks' solution & 6 & Present study \\
\hline$\alpha$-ТCP & MOCVD & Hanks' solution & 336 & Present study \\
\hline $\begin{array}{c}\mathrm{CaTiO}_{3} \\
\text { complicated surface }\end{array}$ & MOCVD & Hanks' solution & 72 & 10) \\
\hline HAp & Plasma spray & SBF & 24 & 15) \\
\hline HAp & Sintering & SBF & 48 & 16) \\
\hline $\mathrm{ACP}$ & Sputtering & $\operatorname{PBS}(-)$ & 120 & 17) \\
\hline HAp & Sintering & Hanks' solution & 168 & 19) \\
\hline HAp & Sol-gel & SBF & 192 & 21) \\
\hline $\mathrm{CaTiO}_{3}$ & Sputtering & Hanks' solution & 168 & 20) \\
\hline
\end{tabular}

tion in a pseudo-body fluid. Therefore, MOCVD would be appropriate for the preparation of bio-ceramics coatings, and the $\mathrm{CaTiO}_{3}, \alpha$-TCP and HAp coatings prepared by MOCVD were promising as bone conductive materials.

\section{Conclusion}

$\alpha$-TCP and HAp coatings were prepared on CP-Ti by MOCVD using $\mathrm{Ca}(\mathrm{dpm})_{2}$ and $\left(\mathrm{C}_{6} \mathrm{H}_{5} \mathrm{O}\right)_{3} \mathrm{PO}$ precursors and were immersed in a Hanks' solution. The apatite phase has formed on the $\alpha$-TCP coating after $1 \mathrm{~d}$ and covered the whole surface after $14 \mathrm{~d}$. The HAp coating eluted into solution in an initial stage, and the apatite phase covered the whole surface after $6 \mathrm{~h}$. The nucleation of apatite occurred preferentially at hollow places of the $\alpha$-TCP and HAp coatings. Ca-P-O coatings prepared by MOCVD could be promising materials having excellent bone conductivity.

\section{Acknowledgements}

This study was partially supported by the Japan Society for the Promotion of Science (JSPS), by Grant-in-Aid for Scientific Research (B), 18360310, by Grant-in-Aid for JSPS fellows, by the Asian CORE program and by Tohoku University Global COE project on material integration.

\section{REFERENCES}

1) W. Suchanek and M. Yoshimura: J. Mater. Res. 13 (1998) 94-117.

2) A. Yamamoto, R. Honma and M. Sumita: J. Biomed. Mater. Res. 39
(1998) 331-340.

3) M. Papakyriacou, H. Mayer, C. Pypen, H. Plenk Jr. and S. StanzTschegg: Int. J. Fatigue 22 (2000) 873-886.

4) D.-M. Liu, T. Troczynski and W. J. Tseng: Biomaterials 22 (2001) 1721-1730.

5) W. Wheng: J. Am. Ceram. Soc. 82 (1999) 27-32.

6) H. Ji, C. B. Ponton and P. M. Marquis: J. Mater. Sci.: Mater. Med. 3 (1992) 283-287.

7) I. Baltag, K. Watanabe, H. Kusakari, N. Taguchi, O. Miyakawa, M. Kobayashi and N. Ito: J. Biomed. Mater. Res. 53 (2000) 76-85.

8) T. Narushima, K. Ueda, T. Goto, H. Masumoto, T. Katsube, H. Kawamura, C. Ouchi and Y. Iguchi: Mater. Trans. 46 (2005) 2246-2252.

9) K. Yamashita, T. Arashi, K. Kitagaki, S. Yamada and T. Umegaki: J. Am. Ceram. Soc. 77 (1994) 2401-2407.

10) R. Tu and T. Goto: Mater. Sci. Forum. 475-479 (2005) 1219-1222.

11) M. Sato, R. Tu and T. Goto: Mater. Trans. 48 (2007) in press.

12) M. Sato, R. Tu, T. Goto, K. Ueda and T. Narushima: Mater. Trans. 48 (2007) 1505-1510.

13) R. Tu, T. Kimura and T. Goto: Mater. Trans. 43 (2002) 2354-2356.

14) H. Yuan, B. J. De, Y. Li, J. Feng, Z. Yang, K. De Groot and X. Zhang: J. Mater. Sci., Mater. Med. 12 (2001) 7-13.

15) J. Weng, Q. Liu, J. G. C. Wolke, D. Zhang and K. De Groot: J. Mater. Sci. Lett. 16 (1997) 335-337.

16) M. Ueshima, S. Makamura, M. Ohgaki and K. Yamashita: Solid State Ionics 151 (2002) 29-34.

17) K. Ueda, T. Narushima, T. Goto, M. Taira and T. Katsube: Biomed. Mater. 2 (2007) S160-S166.

18) P. Siriphannon, Y. Kameshima, A. Yasumori, K. Okada and S. Hayashi: J. Biomed. Mater. Res. 52 (2000) 30-39.

19) L. M. Hirakata, M. Kon and K. Asaoka: Bio-Med. Mater. Eng. 13 (2003) 247-259.

20) K. Asami, K. Saito, N. Ohtsu, S. Nagata and T. Hanawa: Surf. Interface Anal. 35 (2003) 483-488.

21) C. E. Wen, W. Xu, W. Y. Hu and P. D. Hodgson: Acta Biomater. 3 (2007) 403-410. 